\title{
Osteoarticular amyloidosis associated with haemodialysis: an immunoultrastructural study
}

\author{
M DEPIERREUX, M GOLDMAN, ISABELLE FAYT, C RICHARD, J QUINTIN, \\ M DHAENE, J-L VAN HERWEGHEM
}

From the Cliniques Universitaires de Bruxelles, Hôpital Erasme, Université Libre de Bruxelles, Belgium

SUMMARY Osteoarticular amyloidosis occurred in a patient receiving long term haemodialysis. $\frac{\overrightarrow{0}}{0}$ Histological examination showed that the amyloid deposit was surrounded by inflammatory cells and $\oplus$ macrophages filled with haemosiderin. Electron microscopy showed that the amyloid fibrils were in $\vec{\sim}$ close contact with cytoplasmic expansions, or located in intracytoplasmic pockets of the infiltrating $\vec{G}$ cells. Immunohistological and immunoultrastructural observations confirmed that $\beta_{2}$-microglobulin ${ }_{\circ}$ was a major constituent of amyloidosis associated with dialysis. Amyloid P component was also detected within the amyloid deposits.

These findings suggest that amyloid P component, iron overload, or macrophage derived factors $\frac{\mathbb{T}^{\circ}}{\sigma}$ could have a role in the polymerisation of $\beta_{2}$-microglobulin into amyloid deposit.

A new form of amyloid disease has recently been recognised as a long term complication of haemodialysis. ${ }^{1-3}$ Carpal tunnel syndrome, destructive arthropathy, and bone defects are the most salient clinical features of the syndrome, ${ }^{4-6}$ indicating a preferential deposition of amyloid substance in the osteoarticular tissues. Sequence analysis of amino acids obtained from amyloid fibrils, as well as findings from immunohistochemical studies, have shown that $\beta_{2}$-microglobulin is a principal constituent of amyloid deposits in patients being treated by haemodialysis.? This protein accumulates in patients with end stage renal failure, ${ }^{8}$ and conventional haemodialysis with cuprophane membranes cannot remove $\beta_{2}$-microglobulin. ${ }^{39}$ Furthermore, in vitro studies have shown that polymerisation of $\beta_{2}$-microglobulin may lead to formation of amyloid fibrils, ${ }^{10}$ and polymers of the protein have indeed been shown in amyloidosis associated with dialysis."

The factors leading to $\beta_{2}$-microglobulin deposition and amyloid formation in this new form of amyloidosis remain to be determined. In particular, the mechanisms responsible for the preferential accumulation of $\beta_{2}$-microglobulin-derived amyloid in the synovia are still unknown, and the possible adjuvant role of other proteins or inflammatory cells has to be considered.
In this paper we report a case of amyloidosis associated with dialysis in which the cellular envi-응 ronment of the deposits as well as their chemical composition were studied both at histological and ultrastructural levels.

\section{Case report}

A 53 year old woman with end stage renal failure secondary to polycystic kidney disease had been receiving haemodialysis for 15 years with cupro- -8 phane membranes. She had severe secondary hyper- 0 parathyroidism, which required subtotal parathyroidectomy and also aluminium osteomalaciaô which was treated by deferrioxamine. From $1984 \gtrless$ onwards she developed a destructive spondylarthro-윽 pathy affecting the lumbar spine, a right carpal tunnel $\triangleright$ syndrome, and a lytic lesion of the right femoral head. She was admitted for prosthetic replacement of the right hip. At operation severe hypertrophy of the synovial tissues was noted, and the femoral head $N$ displayed a depressed area on the lateral side of the ${ }_{\omega}^{N}$ articular surface.

After surgery tissue blocks were fixed in Bouin'so fixative, embedded in paraffin, and routinely processed for optical observation. Sections stained with $\stackrel{\odot}{?}$ Congo red before and after potassium permanganate 70 "treatment" 12 were examined by conventional and polarised light microscopy.

Immunohistochemical studies were carried out $\stackrel{\vec{\Omega}}{\Omega}$ 
using a rabbit peroxidase-antiperoxidase method ${ }^{13}$ after incubation with anti-human $\kappa$ or $\lambda$ light chain (Becton Dickinson), anti-human $\beta_{2}$-microglobulin (Dakopatts), anti-human amyloid $\mathbf{P}$ component (Dakopatts), and anti-human amyloid AA (Behring Diagnostics) monospecific antibodies. All the primary antisera were diluted $1 / 1000$.

Small pieces of tissue were immersed in $4 \%$ glutaraldehyde, treated with osmium tetroxide, and embedded via propylene oxide into epon. Ultrathin sections were cut and observed with a Philips 400T electron microscope after staining with uranyl acetate and lead citrate.

The immunogold technique was performed as previously described ${ }^{14}$ with minor modifications: tissues were fixed for two hours in $4 \%$ paraformaldehyde and $0.1 \%$ glutaraldehyde in phosphate buffer, washed overnight in buffer, dehydrated, and embedded in LR white resin (TAAB Laboratories, England). Sections $(50 \mathrm{~nm})$ mounted on nickel grids were etched with $10 \%$ distilled water for 10 minutes, incubated with normal goat serum (diluted 1/10) for 30 minutes, and then with anti- $\beta_{2}$-microglobulin or anti-amyloid $P$ component antibodies (diluted 1/1000) for 24 hours. After washing in $0.02 \mathrm{M}$ Tris buffered saline $(\mathrm{pH} \mathrm{8.2)}$ containing $01 \%$ bovine serum albumin, grids were incubated for one hour with gold labelled goat antirabbit immunoglobulin antibodies, diluted 1/20 (Janssens Pharmaceuticals, Belgium). The size of the gold particles was $10 \mathrm{~nm}$.

\section{Results}

The cystic lesion of the femoral head was filled with brown haemorrhagic friable material, surrounded by medullary bone. Hematoxylin and eosin stained slides showed granulation tissue separated by thin strands of fibrosis. The granular, amorphous deposits were surrounded by numerous giant cells, macrophages filled with haemosiderin, fibroblasts, some lymphocytes and plasma cells (fig 1a). Other areas comprised acellular granular material and fibrosis. Deposits of positive substance for Congo red were observed on all tissue sections, and by polarised light microscopy showed green dichroism characteristic of amyloid (fig 1b)(the Congo red affinity and dichroism were reduced by treatment beforehand of the sections with potassium permanganate). Amyloid was also observed in adjacent hyperplastic synovial tissues, which contained inflammatory cells and numerous macrophages laden with haemosiderin pigments.

Immunoperoxidase methods showed no clear reaction of the amyloid deposits with anti-human amyloid A, anti-human $\kappa$ or $\lambda$ light chains antibodies. With anti-human $\beta_{2}$-microglobulin antibodies, the amyloid deposits gave a distinctly positive reaction (fig 1c).
Anti-amyloid $\mathbf{P}$ component also gave a positive reaction, and this has located at the same level as anti- $\beta_{2^{-}}$ microglobulin (fig 1d). The amyloid substance formed in the bone and in the synovial tissue displayed the same immunohistochemical characteristics.

Electron microscopical examination showed that the amyloid deposits were composed of fibres of about $8 \mathrm{~nm}$ in diameter. In the cellular areas the amyloid fibrils were disposed in aggregates separated by thin collagen bundles. When giant cells, fibroblasts, and inflammatory cells were present the amyloid fibrils were in close contact with cytoplasmic expansions or located in intracytoplasmic pockets (fig 2). Some cells seemed to be filled with amyloid and mummified.

Ultrastructural immunochemical observations indicated binding of the anti- $\beta_{2}$-microglobulin antibodies to amyloid fibrils. With anti-amyloid $\mathbf{P}$ antibodies, similar binding was observed but of lower intensity (fig 2 inset). No gold particles were seen around amyloid fibrils after incubation with antiamyloid $\mathbf{A}$, anti- $\kappa$ or $\lambda$ light chain antibodies. The collagen areas did not show any binding of the tested antibodies.

\section{Discussion}

The clinical features of our patient were typical of amyloid disease associated with long term haemodialysis. Indeed, carpal tunnel syndrome, erosive arthropathy, and bone lytic lesions are the cardinal signs of the syndrome. ${ }^{45}$ The amyloid substance has been found to be sensitive to potassium permanganate treatment, which is usually the case in this form of amyloidosis. ${ }^{7}$ Such a finding may suggest the presence of amyloid AA, ${ }^{7}$ but immunoperoxidase staining with anti-amyloid $\mathbf{A}$ protein antibodies was negative, confirming previous observations on similar cases. ${ }^{6}$ Evidence for a crucial role of $\beta_{2}$-microglobulin in the pathogenesis of amyloidosis associated with dialysis was recently provided by biochemical and immunohistochemical studies. ${ }^{37}$ The role of $\beta_{2}$ microglobulin in the amyloid disease of our patient was confirmed by immunological staining both at the histological and at the ultrastructural levels.

The pathogenetic mechanisms leading to the arrangement of $\beta_{2}$-microglobulin into amyloid fibrils are unclear. Serum concentrations of the protein are considerably increased in patients with end stage renal failure, but within the population of patients treated with haemodialysis there is no association between the occurrence of amyloidosis and $\beta_{2}$-microglobulin serum concentrations. ${ }^{3}$ The amyloid substance contains polymers of $\beta_{2}$-microglobulin, but the circulating form of the protein has been shown to be exclusively monomeric." These data, together with the preferential localisation of the amyloid substance in the 

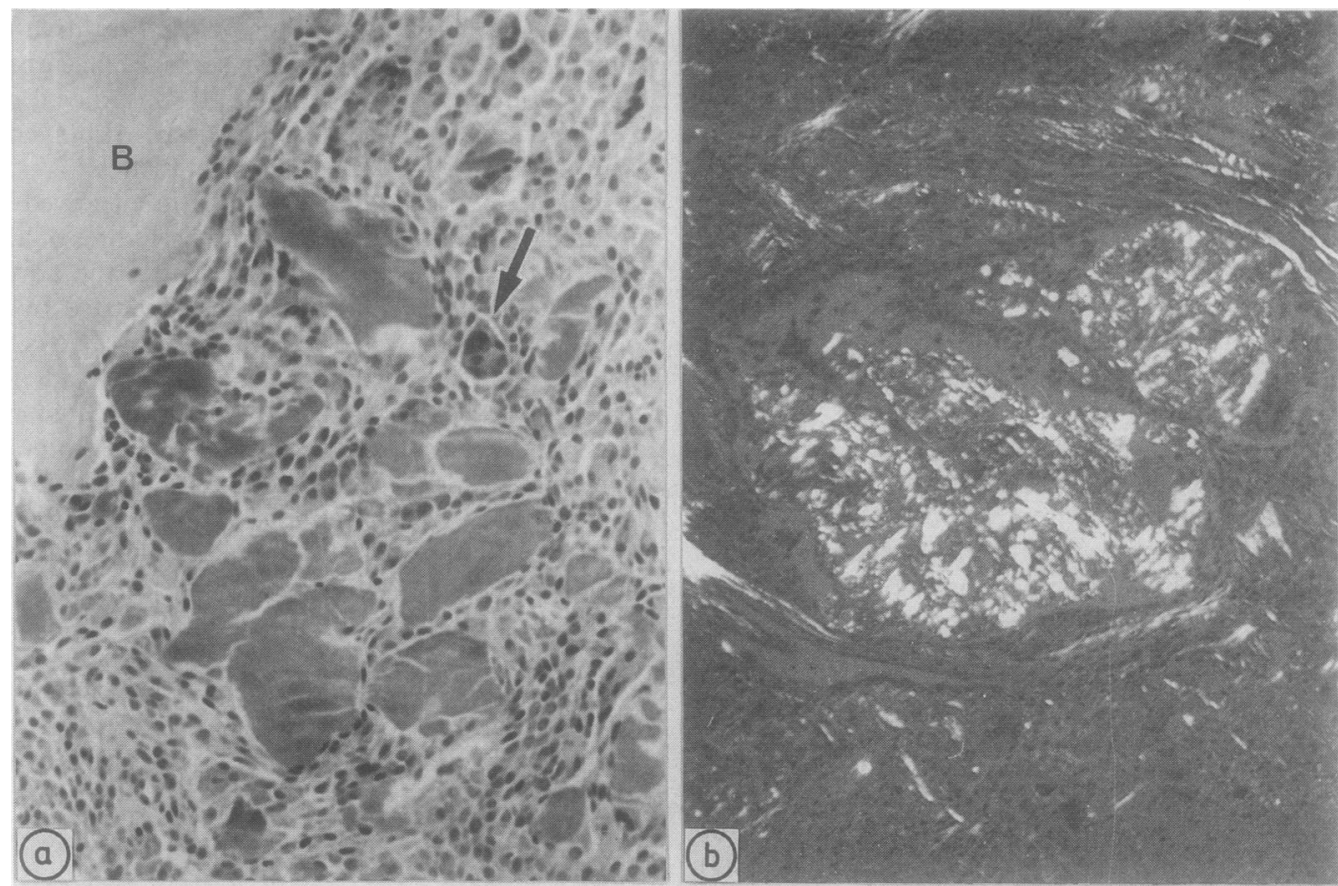

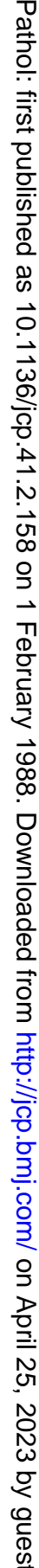
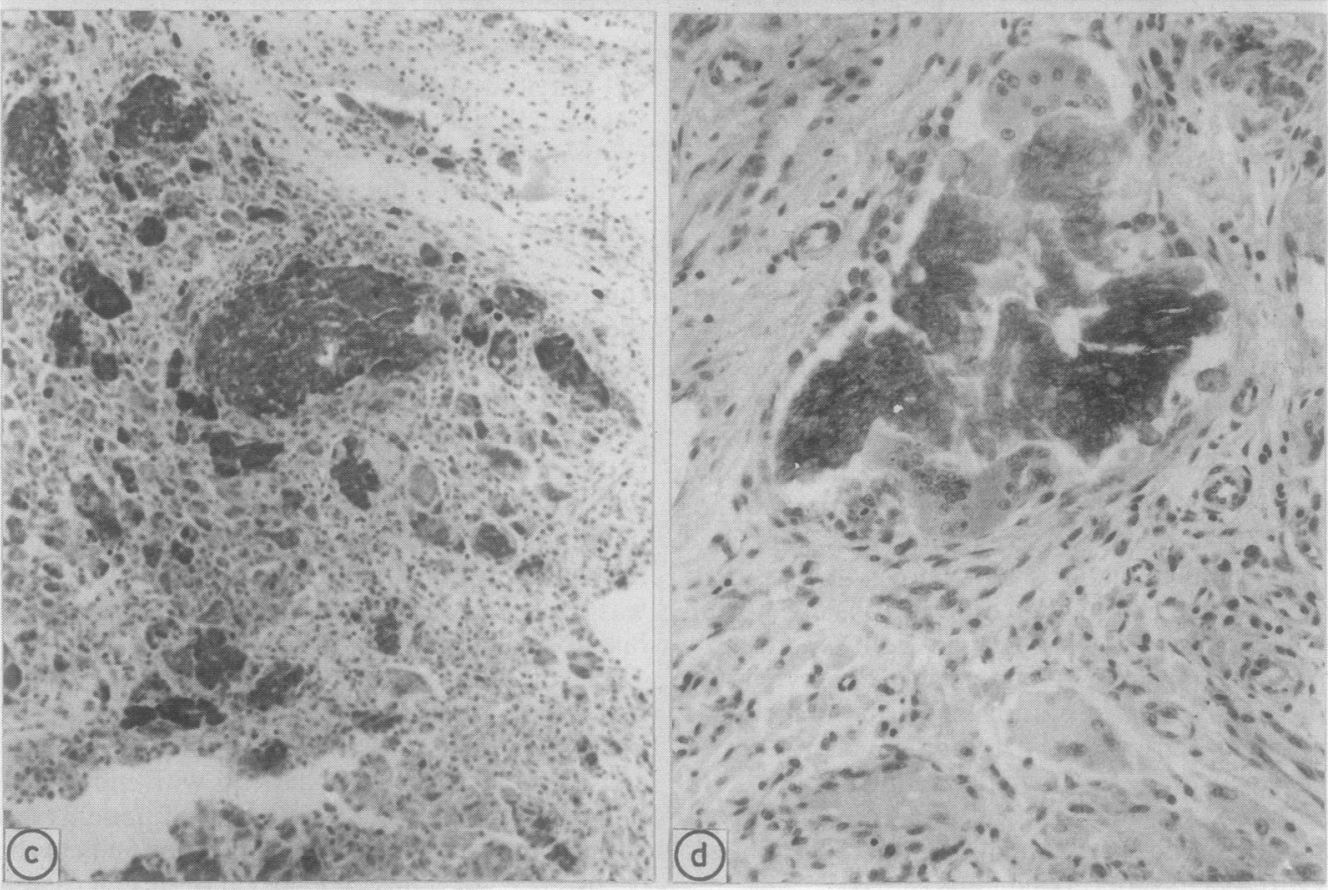

Fig 1(a) Granular deposits in vicinity of cortical bone (B) surrounded by giant (arrow) and inflammatory cells. (b) Dichroism of amyloid deposits under polarised light microscopy. (c) Immunoperoxidase staining of amyloid deposits with anti-human $\beta_{2}$-microglobulin antiserum. (d) Reaction of amyloid $P$ component antiserum with the same amyloid material. 


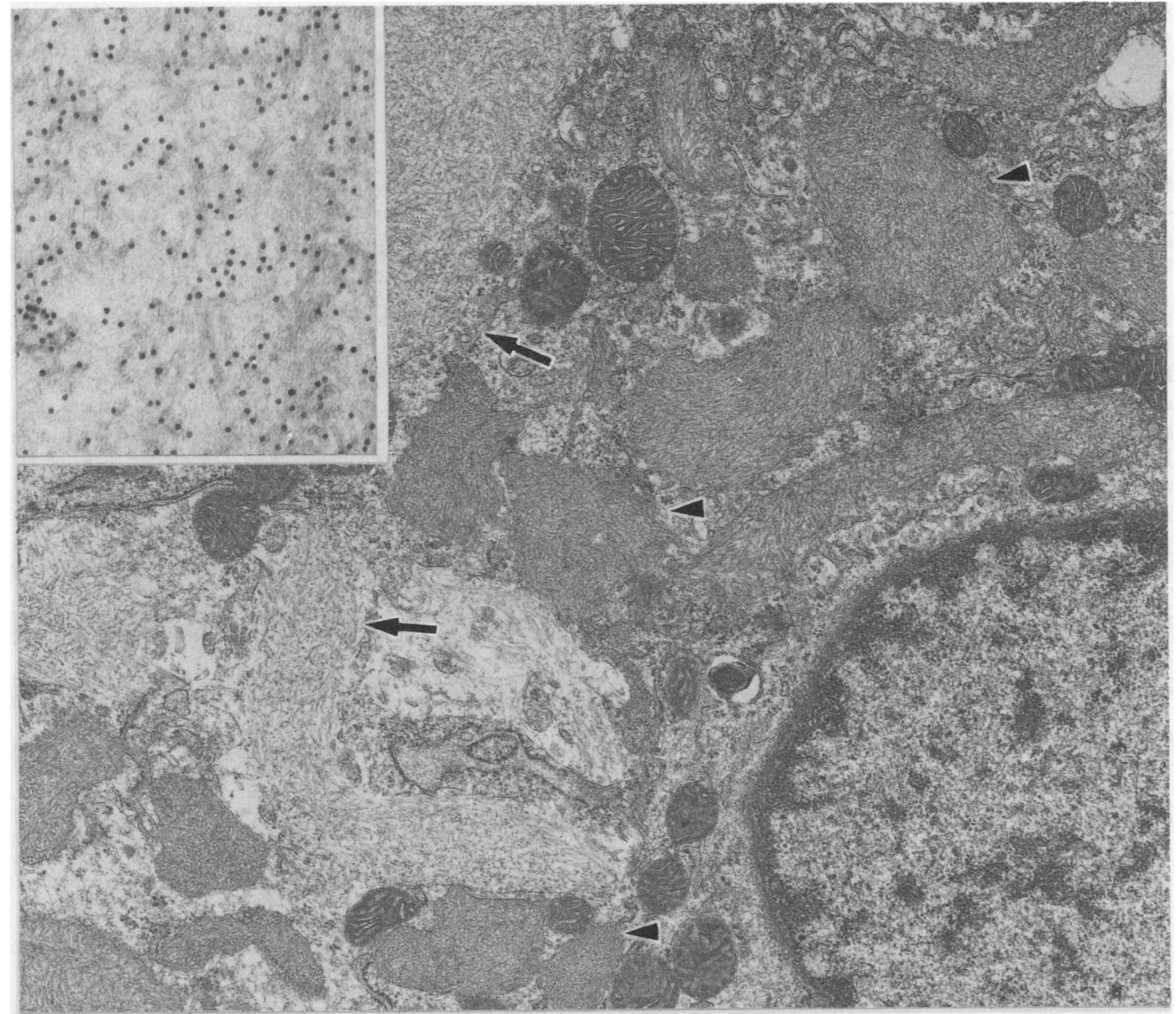

Fig 2 Uttrastructural studies: amyloid fibrils located around (arrows) and within intracytoplasmic pockets (arrow heads). Inset: immunogold labelling of amyloid fibrils with anti- $\beta_{2}-$ microglobulin antibodies.

osteoarticular tissues suggest that unknown factors promote the formation of amyloid fibrils derived from $\beta_{2}$-microglobulin. Iron has recently been suggested as a possible enhancing factor, ${ }^{15}$ and haemosiderin was indeed abundant in the synovial tissue of our patient. Iron overload, however, is a common complication of long term haemodialysis, ${ }^{16}$ and its association with amyloidosis may thus be fortuitous. The demonstration by immunohistochemistry of amyloid P component in the amyloid deposits of our patient was consistent with the biochemical data recently reported by Gorevic et al, " who showed the role of amyloid $\mathbf{P}$ component in this type of amyloidosis by two dimensional electrophoresis followed by immunoblotting of solubilised amyloid fibrils.

Our studies allowed us to visualise deposition of amyloid $\mathrm{P}$ component in association with $\beta_{2}$ microglobulin. Amyloid $\mathbf{P}$ component is associated with other forms of amyloidosis ${ }^{17}$ and could play a facilitating role in the formation of amyloid fibrils. ${ }^{18}$ The metabolism of amyloid $\mathbf{P}$ component in patients with end stage renal failure has not been extensively studied but preliminary data in our laboratory indicate that serum concentrations of the protein are increased in patients treated with haemodialysis.

In amyloidosis associated with immunoglobulin light chain or with the amyloid A protein the formation of amyloid fibrils requires proteolytic digestion of the serum precursor proteins. Monocytes and macrophages are thought to be responsible for this process. ${ }^{19}$ As in our case, macrophages and multinucleated giant cells were indeed often observed around amyloid 
deposits. ${ }^{2}$ Our observation of amyloid fibrils within the cytoplasm of some of these cells would suggest that they actively participate in pathogenesis, either by degrading or by generating $\boldsymbol{\beta}_{2}$-microglobulin-derived amyloidosis. Interestingly, haemodialysis has been shown to affect monocyte function and particularly to promote interleukin-1 generation. ${ }^{20} \mathrm{~A}$ possible association between interleukin-1 production and amyloidosis associated with dialysis has already been suggested. ${ }^{21}$

Amyloidosis associated with dialysis is mainly observed in patients treated with cuprophane membranes.' This may be related to the inability of these membranes to clear $\beta_{2}$-microglobulin or to their so called bioincompatibility, resulting in activation of different biological systems including interleukin-1.22 Further studies are required to clarify the mechanisms responsible for this new type of amyloidosis to define new strategies which would prevent this major complication of long term haemodialysis.

This study was supported by a grant of the Fonds pour la Recherche Scientifique Médicale (no 3.4517.84), the David and Alice van Buuren Foundation, and by a grant from Gambro.

We thank Mrs A M Couck and Mr P Lambert for excellent technical assistance.

\section{References}

1 Clanet M, Mansat M, Durroux R, et al. Syndrome du canal carpien, ténosynovite, amyloìde et hémodialyse périodique. $R e v$ Neurol (Paris) 1981;137:613-24.

2 Morita T, Suzuki M, Kamimura A, Hirasawa Y. Amyloidosis of a possible new type in patients receiving long-term hemodialysis. Arch Pathol Lab Med 1985;109:1029-32.

3 Gejyo F, Odanis S, Yamada T, et al. $\beta_{2}$-microglobulin: a new form of amyloid protein associated with chronic hemodialysis. Kidney Int 1986;30:385-90.

4 Durroux R, Bennouaich L, Bouissou H. Ténosynovite du canal carpien et dépôts d'amyloide chez les insuffisants rénaux chroniques hémodialysés. Nouv Presse Med 1981;10:45.

5 Bardin T, Kuntz D, Zingraff J, Voisin MC, Zelmar A, Lansaman J. Synovial amyloidosis in patients undergoing long-term hemodialysis. Arthritis Rheum 1985;281052-8.

6 Casey TT, Stone WJ, Diraimondo CR, et al.Tumoral amyloidosis of bone of beta 2 microglobulin origin in association with long term hemodialysis: a new tye of amyloid disease. Hum Pathol 1986;17:731-8.

7 Shirahama T, Skinner M, Cohen AS, et al. Histochemical and $\underline{\partial}$ immunohistochemical characterisation of amyloid associated with chronic hemodialysis as $\beta_{2}$-microglobulin. Lab Invest $\overrightarrow{\vec{\omega}}$ 1985;53:705-9.

8 Wibell L, Evrin PE, Berggard I. Serum $\beta_{2}$-microglobulin in renal disease. Nephron 1973;10:320-31.

9 Vandenbrouck JM, Jadoul M, Maldague B, et al. Possible role of dialysis membrane characteristics in amyloid osteoarthropathy. $\frac{\vec{D}}{\mathrm{Q}}$ Lancet 1986;:1210-11.

10 Connors LH, Shirahama T, Skinner M, Fenves A, Cohen AS. In ڤ్ vitro formation of amyloid fibrils from intact $\beta_{2}$-microglobulin. Biochem Biophys Res Com 1985;131:1063-8.

11 Gorevic P, Munoz PC, Casey TT, et al. Polymerisation of intact $\beta_{2^{-}}-\overrightarrow{-}$ microglobulin in tissue causes amyloidosis in patients on $\vec{\omega}$ chronic hemodialysis. Proc Natl Acad Sci USA 1986;83: O 7908-12.

12 Wright JR, Calkins E, Humphrey RL. Potassium permanganate reaction in amyloidosis. A histologic method to assist in differentiating forms of this disease. Lab Invest 1977;36:274-81. N

13 Sternberger LA. Immunocytochemistry. 2nd ed. New York: John $\vec{G}$ Wiley and Sons, 1979: 104-69.

14 Brion JP, Couck AM, Flament-Durand J, D'haens J, Mockel J.을 Demonstration of prolactin at the ultrastructural level in a pituitary adenoma by the use of colloidal gold labelling. $\vec{J}_{T}$ Submicrosc Cytol 1984;16:555-60.

15 Cary NRB, Sethi D, Brown EA, Erhardt CC, Woodrow D, Gower을 PE. Dialysis arthropathy: amyloid or iron? Br Med J 1986; 293:1392-4.

16 Goldman M, Van Herweghem JL. Multiple blood transfusion and iron overload in patients receiving hemodialysis. Nephrol DiakO Transplant 1987;2:205-7.

17 Shirahama T, Skinner M, Westemark P, et al. Senile cerebral amyloid: prealbumin as a common constituent in the neuritico plaque, in the neurofibrillary tangle and in the microangiopathics lesion. Am J Pathol 1982;107:41-50.

18 Pepys MB, Dyck RC, De Beer FC, Skinner M, Cohen AS. Bindingo of serum amyloid P component (SAP) by amyloid fibrils. Clin Exp Immunol 1979;38:284-93.

19 Glenner GG, Page DL. Amyloid, amyloidosis and amyloidogen $\overrightarrow{\vec{B}}$ esis. Int Rev Exp Pathol 1976;15:1-92.

20 Bingel M, Lonnemann G, Koch KM, Dinarello CA, Shaldon S. Enhancement of in-vitro human interleukin-1 production by sodium acetate. Lancet 1987;i:14-16.

21 Flöge J, Granolleras C, Bingel M, et al. Beta 2 microglobulin kinetics during hemodialysis and hemofiltration. Nephrol Diaf Transplant 1987;1:223-8.

22 Henderson LW, Koch KM, Dinarello CA, Shaldon S Hemodialysis hypotension: the interleukin hypothesis. Blood Purification 1983;1:3-8.

Requests for reprints to: $M$ Depierreux, Service d'Anatomie Pathologique, CUB Hôpital Erasme, 808, route de Lennik, 1070 Brussels, Belgium. 